\title{
Nostra Aetate: Sebuah alternatif menuju keharmonisan di tengah suburnya intoleransi dan diskriminasi
}

\author{
Martina Novalina', Grant Nixon², Erastus Sabdono ${ }^{3}$, \\ Sonny Zaluchu ${ }^{4}$, Eliza Christabella Phuanerys ${ }^{5}$ \\ 1,2,3Sekolah Tinggi Teologi Ekumene Jakarta \\ ${ }^{4}$ Sekolah Tinggi Teologi Baptis Indonesia, Semarang, Jawa Tengah \\ ${ }^{5}$ Universitas Bunda Mulia, Jakarta \\ Correspondence: martina@sttekumene.ac.id
}

https://orcid.org/0000 0003-2489-5980

Keywords:

discrimination; harmony; intolerance; Nostra Aetate; diskriminasi; intoleransi; keharmonisan

\section{Article History}

Submitted: July 19, 2021

Revised: August 22, 2021

Accepted: August 31, 2021

DOI: https://doi.org/

10.30995/kur.v7i2.340

Copyright: $\bigcirc 2021$, Authors.

License:

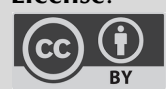

Scan this QR,

Read Online

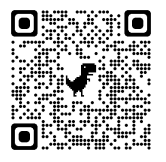

Abstract: The Covid 19 pandemic has an impact on various life lines. One of them is the increasing rate of discrimination and intolerance experienced by various people from various religions and groups. Many ways have been done for the loss of intolerance and discrimination in Indonesia but there are still such actions. This paper proposes the concept of dialogue based on the declaration of Nostra Aetate. The main approach taken in this paper is critical theory to descriptively analyze the main concepts discussed, namely Nostra Aetate and harmony dialogue. The result is that the declaration of Nostra Aetate is an alternative offer that can be taken in Indonesia to convey God's love to people through several ways of dialogue, pastoral, and harmonious.

Abstrak: Pandemi Covid 19 memberi dampak di berbagai lini kehidupan. Salah
satunya adalah meningkatnya angka diskriminasi dan intoleransi yang dialami
oleh berbagai kalangan masyarakat dari berbagai penganut agama maupun
golongan. Banyak cara telah dilakukan demi hilangnya intoleransi dan diskri-
minasi di Indonesia namun masih saja terdapat tindakan-tindakan tersebut.
Paper ini mengusulkan konsep dialog yang bertumpu pada deklarasi Nostra
Aetate. Pendekatan utama yang dilakukan dalam paper ini adalah teori-kritik
(critical theory) untuk menganalisis secara deskriptif konsep-konsep utama
yang dibahas yakni Nostra Aetate dan dialog kerukunan. Hasil yang didapat
adalah bahwa deklarasi Nostra Aetate merupakan sebuah tawaran alternatif yang
dapat diambil di Indonesia guna menyampaikan kasih Allah kepada manusia me-
lalui beberapa cara dialogis, pastoral, dan harmonis.

\section{Pendahuluan}

Setara Institute dalam laporan risetnya tentang situasi terkini Kebebasan Beragama/Berkeyakinan (KBB) di Indonesia menyimpulkan bahwa sepanjang tahun 2020 telah terjadi peningkatan eskalasi pelanggaran KBB, dari semula 327 kasus naik menjadi 422 kasus. ${ }^{1}$ Dalam laporannya, Setara Institute membeberkan bahwa pandemi covid 19 menjadi katalis kasus-kasus diskriminasi dan intoleransi di Indonesia. Pandemi memberikan ruang dan waktu bagi setiap orang untuk memiliki akses pada media sosia. Situasi tersebut signifikan dengan membanjirnya konten-konten yang bermuatan kebencian, penghinaan terhadap tokoh agama, pelecehan agama dan hoax di berbagai media sosial. Pelaku pelanggaran berasal dari kalangan aktor negara (tertinggi: peme-

${ }^{1}$ Setara Institute, "Memahami Situasi Intoleransi," 2021, accessed May 7, 2021, https://setarainstitute.org/memahami-situasi-intoleransi/. 
rintah daerah dan kepolisian) dan non-negara (tertinggi: kelompok warga dan ormas keagamaan). Korbannya adalah masyarakat Indonesia sendiri. ${ }^{2}$

Isu intoleransi bukanlah hal baru yang ada di Indonesia. Sebelum pandemi Covid-19, sudah ada beberapa kejadian intoleransi yang menarik perhatian publik bahkan sampai ke mancanegara. ${ }^{3}$ Melihat situasi tersebut, banyak pihak melakukan kajian penelitian dengan berbagai macam sudut pandang dan hasil. Penelitian Haryani, berhasil menyusun model kerukunan umat beragama melalui studinya di kota Bogor, salah satu kota di Indonesia yang dilaporkan tertinggi dalam kasus intoleransi. Akibat pemahaman agama yang rigid dan statis, intoleransi menjadi subur. Tetapi Haryani melihat bahwa kerukunan bukanlah sesuatu yang sulit ditempuh. Temuannya tentang sebuah desa di Pabuaran membuktikan bahwa model desa kerukunan dapat dikembangkan melalui peace train, dan Forum Kerukunan Umat Beragama (FKUB). Model ini dapat dijadikan solusi mengubah kota Bogor dari intoleran menjadi kota kerukunan. ${ }^{4}$

Penelitian berikutnya dilakukan oleh Muhaemin dan Sanusi. Melalui penelitian media, terhadap surat kabar Kompas, ditemukan bahwa penyebab suburnya intoleransi adalah pemahaman agama yang dangkal, parsial, dan tidak mendalam. Penelitian itu sekaligus melihat bahwa jika hal tersebut dibiarkan maka NKRI dapat berada dalam bahaya. Keduanya merekomendasikan agar pemerintah bertindak sedini mungkin untuk membereskan hal tersebut, dengan melibatkan tokoh agama, serta melakukan penanganan yang sifatnya non-politis. Tujuannya, untuk membangun komunikasi dialogis yang intens tetapi kontinu dalam mengedukasi masyarakat agar memiliki kesadaran terhadap keberagamaan. ${ }^{5}$ Rekomendasi penelitian ini senada dengan program yang sedang digaungkan oleh Kemenag dan Kemenlu, di mana moderasi beragama saat ini bukan hanya menjadi kebutuhan di dalam negeri saja, tetapi juga mendesak sebagai sebuah agenda global. ${ }^{6}$

Akar konseptual dari intoleransi adalah konservatisme sempit, di mana praktik dan epistemologi agama lebih ditekankan kepada kebenaran sepihak yang kuat di dalam tradisi dan nilainilai lama. Gelombang konservatisme ini menguat di Indonesia pasca kejatuhan orde baru di mana semua orang terbuai oleh kebebasan berbicara atas nama demokrasi. ${ }^{7}$ Menyikapi situasi tersebut, Novalina menyarankan perlunya perbaikan konsep-konsep spiritualitas di tengah masyarakat. Eskpresi keagamaan tidak harus diarahkan kepada hal-hal destruktif dan intoleran, yang berpotensi menghancurkan kesatuan dan keragaman yang selama ini telah terbentuk. ${ }^{8} \mathrm{Hal}$ ini menjadi pekerjaan rumah seluruh orang Indonesia. Ide-ide yang dapat dikembangkan untuk mempertahankan ikatan kovalen kerukunan umat beragama harus dipelajari dan dipikirkan karena Indonesia adalah sebuah rumah bersama. Dialog dapat dikembangkan hingga ke ranah digital demi keutuhan keindonesiaan. Di antara sekian banyak model dan pengembangan kerukunan, artikel ini mengusulkan konsep dialog yang bertumpu pada deklarasi Nostra Aetate.

\footnotetext{
${ }^{2}$ Ibid.

3 "Vonis penjara Ahok lewat kaca mata media internasional," BBC News Indonesia, 2021., accessed May 8, 2021, https://www.bbc.com/indonesia/dunia-39855994; mediaindonesia com developer, "Kasus Intoleransi di Indonesia Jadi Sorotan Internasional," last modified May 30, 2018, accessed May 8, 2021, https://mediaindonesia.com/internasional/163651/kasus-intoleransi-di-indonesia-jadi-sorotan-internasional; Kompas Cyber Media, "Imparsial: Intoleransi Masih Jadi Masalah yang Terus Berulang di Indonesia," KOMPAS.com, last modified November 17, 2019, accessed May 8, 2021,

https://nasional.kompas.com/read/2019/11/17/16015521/imparsial-intoleransi-masih-jadi-masalah-yang-terusberulang-di-indonesia.

${ }^{4}$ Elma Haryani, "Intoleransi Dan Resistensi Masyarakat Terhadap Kemajemukan: Studi Kasus Kerukunan Beragama Di Kota Bogor, Jawa Barat," Harmoni 18, no. 2 (December 31, 2019): 73-90.

${ }^{5}$ Irfan Sanusi and Enjang Muhaemin, "Intoleransi Keagamaan Dalam Framing Surat Kabar Kompas," Communicatus: Jurnal Ilmu komunikasi 3, no. 1 (June 25, 2019): 17-34.

${ }^{6}$ Kementrian Agama, "Kemenag Dan Kemenlu Sinergi Kenalkan Moderasi Beragama Ke Dunia," accessed May 8, 2021, https://kemenag.go.id/read/kemenag-dan-kemenlu-sinergi-kenalkan-moderasi-beragama-ke-dunia-jjk2r.

${ }^{7}$ Luthfi Assyaukanie, "Akar-Akar Legal Intoleransi Dan Diskriminasi Di Indonesia," MAARIF 13, no. 2 (December 20, 2018): 27-42.

${ }^{8}$ Martina Novalina, "Spiritualitas Orang Kristen Dalam Menghadirkan Kerajaan Allah Di Tengah Tantangan Radikalisme," Jurnal Teologi Kontekstual Indonesia 1, no. 1 (June 29, 2020): 26.
} 
Nostra Aetate bertujuan untuk merangkul setiap agama yang kerap terpisah oleh karena perbedaan dogmatis ataupun trauma masa lalu melalui sikap peneriman dan pemahaman satu dengan yang lain dalam sebuah misi menyampaikan kasih Allah kepada manusia.

\section{Metode Penelitian}

Pendekatan utama yang dilakukan dalam artikel ini adalah telaah kritis untuk menganalisa secara deskriptif konsep-konsep utama yang dibahas yakni Nostra Aetate dan dialog kerukunan. Untuk mewujudkan hal itu maka artikel pertama-tama menjelaskan konsep dan historis dari Nostra Aetate lalu menggunakan pemikiran-pemikiran di dalam dokumen itu untuk menjadi ide bagi terciptanya keharmonisan di dalam suasana intoleransi di Indonesia. Sejumlah studi pustaka diperlukan untuk melakukan telaah kritis khususnya dalam mendeskripsikan implementasi praktis konsep-konsep kunci Nostra Aetate. Keseluruhan artikel dikerjakan secara eksploratif, sebagaimana dimaksudkan Zaluchu ${ }^{9}$, terutama dalam mengungkap korelasinya dengan agamaagama di dunia di dalam konteks kekinian.

\section{Pembahasan}

Penafsiran literal terhadap kitab suci dapat berbahaya dalam membentuk pemahaman radikal, dangkal, dan lepas konteks. Terlebih jika hal ini dilakukan oleh awam yang un-educated terhadap proses hermenetika yang benar. Ciri seperti ini umumnya dijumpai di kalangan atau kelompok intoleran yang melihat segala sesuatunya dari kacamatanya sendiri. Bagi kelompok seperti ini, hal yang tertulis secara literal dalam kitab suci tidak memerlukan penafsiran yang kontekstual. ${ }^{10}$ Padahal di sisi lain, zaman telah berubah drastis sehingga beberapa epistemologi dan aksiologi agama sudah menjadi discontinue. Oleh sebab itu, penghalang besar dalam menciptakan kerukunan di tengah masyarakat yang majemuk adalah proses interpretasi teks yang sangat subjektif. Alih-alih berdiskusi satu sama lain untuk tujuan saling memahami ajaran agama, pembenaran dan pemaksaan kebenaran sepihak justru menjadi warna yang kuat dari berbagai dialog yang selama ini terjadi secara global. Situasi seperti ini tentu saja menaburkan bibit-bibit disharmonisasi dan konflik horizontal antar pemeluk agama. Hal inilah yang akhirnya menuntun gereja mengambil sikap untuk berperan mengatasi perbedaan-perbedaan tersebut dalam menjalankan fungsinya sebagai garam dan terang dunia. Nostra Aetate lahir dalam semangat tersebut.

\section{Sejarah Deklarasi Nostra Aetate}

Nostra Aetate ${ }^{11}$, dokumen yang merupakan bagian dari Konsili Vatikan II mengusung tema pembaharuan gereja agar selaras dengan perkembangan zaman. Melalui pembaharuan tersebut gereja dapat tetap aktual di zaman yang berubah dan tetap menjadi kesaksian dalam mempertahankan kasih Allah dan kebenaran-Nya. Dokumen ini lahir dari keprihatinan Gereja Katolik menghadapi keluhan komunitas Yahudi terhadap cap deicidium (pembunuh Tuhan) yang menjadi stigma sejarah alkitabiah. ${ }^{12}$ Inilah salah satu alasan historis mengapa Hitler sangat memperlihatkan politik anti-semit terhadap orang-orang Yahudi.

Demi menghapus stigma historis tersebut, Paus Yohanes XXIII memimpin rekonsiliasi mewakili gereja terhadap komunitas Yahudi. Perwakilan Yahudi memohon gereja untuk menghilangkan penilaian negatif terhadap eksistensi mereka; dan sebaliknya, komunitas Yahudi juga memperbaiki pandangannya terhadap gereja. Kedua belah pihak sepakat mengakhiri intoleransi dan

\footnotetext{
${ }^{9}$ Sonny Eli Zaluchu, "Metode Penelitian Di Dalam Manuskrip Jurnal Ilmiah Keagamaan," Jurnal Teologi Berita Hidup 3, no. 2 (March 2021): 249-266.

${ }^{10}$ Martina Novalina, Di Bawah Kepak Sayap Sang Garuda (Pemahaman, Sikap Dan Tindakan Fundamental Keber-Agama-an Dalam Bingkai Pancasila), ed. Tim STT Ekumene, 1st ed. (Jakarta: Rehobot Literature, 2018).

${ }^{11}$ R. Hardawiryana, "Seri Dokumen Gerejawi No. 10: Dignitatis Humanae - Nostra Aetate" (Departemen Dokumentasi dan Penerangan KWI, 2013), accessed May 8, 2021, http://www.dokpenkwi.org/wpcontent/uploads/2020/01/Seri-Dokumen-Gerejawi-DIGNITATIS-HUMANAE-NOSTRA-AETATE.pdf.

${ }^{12}$ J. Ratzinger, Puntjak-Puntjak Teologis Dalam Konsili Vatikan II (Yogyakarta: Kanisius, 1970).
} 
memperbaiki tulisan masing-masing tentang eksistensi keyahudian/gereja. Hasilnya tertuang dalam sebuah pernyataan sikap resmi Gereja terhadap Yahudi. Namun, rancangan pernyataan tentang sikap Gereja terhadap Yahudi (Naskah A) tidak mendapat respons yang baik dari pihak Arab Muslim. Muncul kekuatiran bahwa dokumen tersebut membawa misi tersembunyi berupa pengakuan negara Israel oleh Vatikan.

Naskah A tersebut kemudian diperbaiki dan berubah menjadi Naskah B yang berisi sikap gereja terhadap agama-agama lain selain Yahudi. Judulnya menjadi "Sikap Gereja Katolik terhadap orang bukan Kristiani, terutama Yahudi". Namun kembali lagi, naskah B tersebut ditolak oleh uskup Arab yang tidak menyetujui Yahudi dimasukkan ke dalam dekrit tentang Ekumenisme. Alasannya doktrinal, ekumenisme hanya berlaku bagi orang-orang yang telah dibaptis dalam nama Kristus. Yahudi menolak Kristus sebagai Tuhan. Naskah B ditarik kembali. Selama penundaan, Paus Paulus VI melakukan kunjungan ke Palestina dan bertemu dengan beberapa pemuka Islam. Hasil kunjungan itu adalah terbentuknya sekretariat bersama antara gereja dengan agama-agama lain, terutama Islam, dalam rangka dialog antara agama.

Proses perbaikan naskah berlanjut kepada Naskah C dengan judul "Deklarasi tentang Orang Yahudi dan Orang Bukan Yahudi". Naskah C berisi bahwa Gereja tidak boleh berdiam diri terhadap bangsa Yahudi karena Yesus dan para rasul sendiri mencintai bangsa Yahudi. Komisi Koordinasi mengusulkan dimasukkan suatu ajakan kepada umat Katolik untuk tidak menyebut bangsa Yahudi sebagai bangsa yang terkutuk dan hendak menampilkan kesatuan Gereja dengan Israel. Namun, hal ini disalahpahami oleh Rabbi Yoshua Hecsel. Baginya pernyataan tersebut adalah sebuah ajakan halus terhadap bangsa Israel untuk menerima iman Katolik. Akibat keberatan dari banyak pihak, naskah $\mathrm{C}$ dijadikan naskah yang berdiri sendiri dan tidak lagi ditangani Sekretariat Ekumenisme, namun oleh panitia khusus.

Dalam perkembangan selanjutnya, naskah C berubah menjadi D dan diberi judul "Deklarasi Tentang Sikap Gereja Terhadap Agama-Agama Non-Kristiani". Pernyataan sikap Gereja terhadap bangsa Yahudi disatukan dengan teologi yang luas tentang agama-agama lain. Namun demikian, tetap saja ditemukan reaksi penolakan dari beberapa pihak seperti Islam-Arab, dan Uskup Ortodoks. Pada akhirnya, sekalipun Naskah D diterima, namun dalam sidang keempat konsili, Naskah D mengalami beberapa perubahan, dan memberi dampak meredanya aksi protes terhadap konsili di luar sidang. Rumusan Naskah terakhir adalah Naskah E yang berjudul "Deklarasi tentang Sikap Gereja terhadap Agama-Agama Bukan Kristiani". Deklarasi ini bersifat mandiri, dan disetujui oleh 2221 orang hasil pemungutan suara. Secara resmi ditetapkan pada tanggal 28 Oktober 1965 dengan nama Nostra Aetate yang diambil dari dua kata pertama deklarasi tersebut; Nostra dan Aetate, yang artinya adalah "Zaman Kita". ${ }^{13}$

\section{Semua Bangsa di Bumi}

Pendahuluan deklarasi Nostra Aetate menyatakan bahwa semua bangsa di bumi berasal dari Allah. Sekalipun berbeda-beda asal usulnya, berkat dan pemeliharaan Allah tetap ada atas bangsa-bangsa. Itulah sebabnya deklarasi ini terlihat menyatakan bahwa perbedaan dogmatik di dalam cara setiap bangsa menjalankan agamanya bukanlah sesuatu yang harus ditonjolkan. Jika pihak-pihak yang berbeda keyakinannya mau menyadari perbedaan tersebut di dalam terang kasih Tuhan, maka intoleransi tidak akan terjadi. Semua orang menyadari sebagaimana dokumen itu nyatakan, memiliki akses terhadap kasih Allah dan menjadi objek pernyataan kasih-Nya. Pendahuluan dokumen itu menegaskan bahwa semua manusia berasal dari satu Allah. Oleh karena itu perdebatan-perdebatan atas perbedaan yang menjurus pada tindakan membinasakan satu dengan yang lain, seharusnya dapat dihindari.

\section{Berbagai Agama bukan Kristiani}

Poin kedua deklarasi Nostra Aetate menyatakan sikap gereja Katolik terhadap agama dan doktrin agama lain. Posisi doktrinal Katolik menjelaskan bahwa dirinya tidak menolak apa pun yang di-

\footnotetext{
${ }^{13}$ R. Hardawiryana, "Seri Dokumen Gerejawi No. 10: Dignitatis Humanae - Nostra Aetate."
} 
anggap benar dan suci dalam agama lain. Gereja bersikap hormat dan tulus merenungkan caracara bertindak dan hidup, kaidah serta ajaran yang memang berbeda dengan dirinya. Dalam perbedaan tersebut, gereja tidak berhenti untuk mewartakan "jalan, kebenaran dan hidup" (Yoh. 14:6) yaitu Kristus itu sendiri. Oleh karena itu, gereja mendorong umat untuk bijaksana dan penuh kasih membangun berdialog antar-iman dan mendorong terbentuknya kerjasama.

Dalam kemajemukan, dialog adalah usaha paling efektif yang dapat dilakukan guna menciptakan kerukunan dan keharmonisan. ${ }^{14}$ Perlu ditegaskan bahwa dialog bukanlah media untuk menyebarkan agama masing-masing, atau memaksa seseorang berpindah keyakinan. Dialog bukan pula sarana untuk mendiskreditkan dan saling memegahkan diri dengan merasa ajaran agamanya yang paling benar. Dialog tidak dimaksudkan untuk menciptakan sebuah teologi universal, tetapi untuk melihat keunikan teologi masing-masing agama.

Ada empat macam model dialog yang dapat dikembangkan demi menciptakan kerukunan dan keharmonisan di dalam kemajemukan menurut Aikot: (a) Dialog kehidupan atau persaudaraan, dimana dalam dialog ini masyarakat menciptakan hubungan erat melalui hidup persaudaraan yang rukun, membangun solidaritas dan subsidiaritas dengan sikap saling peduli dan menyokong dalam hidup bersama; (b) Dialog karya atau kerjasama, dimana para penganut agama yang berbeda bekerja sama dalam segala level, baik lokal, nasional, internasional memberikan kepedulian dan melayani martabat manusia ditengah munculnya bencana alam maupun kejahatan moral; (c) Dialog pandangan teologi, dimana para ahli dalam bidang teologi menyampaikan ajaran dan kebenarannya untuk dipergunakan bersama sebagai kekuatan dalam menghadapi persoalan umat manusia pada umumnya. Hal ini senada dengan tujuan deklarasi Nostra Aetate, di mana titik temu teologis menjadi kekuatan, bukan titik bedanya. Dialog ini tidak boleh memiliki pretensi apa-apa selain berusaha memahami teologi dari setiap agama dan menghargai nilai-nilai rohani yang terkandung di dalamnya. Keterbukaan adalah kunci penting dalam dialog ini; (d) Dialog pengamalan keagamaan atau dialog iman, di mana tujuan dialog ini adalah memperkaya setiap penganut agama melalui sharing pengalaman doa, kontemplasi, maupun meditasi. Dalam dialog ini, penganut agama masing-masing sudah berakar dalam tradisi keagamaannya. Dialog ini adalah merupakan dialog tingkat tinggi. ${ }^{15}$ Seluruh model dialog yang diusulkan Aikot dapat dipraktikan dalam konteks inter-faith.

\section{Pandangan terhadap Keislaman}

Dalam poin ini, deklarasi Nostra Aetate berisi tentang bagaimana gereja menghargai umat Islam yang menyembah Allah yang mahakuasa, Sang Pencipta langit dan bumi. Kaum Muslimin berusaha, dengan segenap hati, menyerahkan diri kepada ketetapan-ketetapan Allah yang monoteistik sebagaimana pandangan serupa dimiliki kaum Nasrani. Kendati doktrinnya tidak mengakui keilahian Yesus, Islam menghormati-Nya sebagai Nabi. Penghormatan yang sama juga diberikan kepada Maria, Bunda Yesus. Deklarasi ini juga menyatakan bahwa Islam sebagai agama mengajarkan pentingnya kehidupan susila, dan menekankan aspek perbuatan seperti berdoa, bersedekah, dan berpuasa sebagai ekspresi bakti kepada Allah. ${ }^{16}$

Tidak dapat dipungkiri, bahwa pertikaian dan permusuhan antara umat Kristiani dan Muslim senantiasa ada di sepanjang zaman, namun melalui deklarasi Nostra Aetate, gereja mendorong umat untuk melupakan yang sudah lalu, dan dengan tulus hati melatih diri untuk memahami satu dengan yang lain, mengampuni dan membela serta mengembangkan keadilan sosial bagi semua orang, dalam kerangka perdamaian.

\footnotetext{
${ }^{14}$ Gavin D'Costa, Christianity and World Religions: Disputed Questions in the Theology of Religions (Chichester, U.K.; Malden, Mass: Wiley-Blackwell, 2009).

15 "Memperkuat Kerukunan Melalui Dialog - Kanwil Kementerian Agama Provinsi Nusa Tenggara Timur," accessed May 8, 2021, https://ntt.kemenag.go.id/berita/510490/memperkuat-kerukunan-melalui-dialog.

${ }^{16}$ R. Hardawiryana, "Seri Dokumen Gerejawi No. 10: Dignitatis Humanae - Nostra Aetate."
} 


\section{Sikap terhadap Diskriminasi}

Poin terakhir dalam deklarasi Nostra Aetate ini berisi tentang kecaman gereja terhadap setiap diskriminasi, baik menurut warna kulit, keturunan, kondisi agama atau hidup yang berlawanan dengan semangat Kristus. Tidak ada dasar bagi setiap teori dan praktik untuk melakukan pembedaan mengenai martabat dan hak-hak manusia. Gereja tegas meminta umat kristiani untuk memelihara cara hidup yang baik di antara bangsa-bangsa bukan Yahudi sebagaimana yang terdapat dalam 1 Petrus 2:12, Roma 12:18, dan Matius 5:45.

Deklarasi Nostra Aetate menunjukkan bahwa keterlibatan antar agama merupakan kunci keberhasilan dalam menghilangkan diskriminasi. Gereja membuka pintu menuju dialog dan keterlibatan yang semakin mendalam dalam mengatasi kesalahpahaman dan distorsi. Setiap penganut agama perlu membayangkan dirinya sebagai bagian dari kemanusiaan bersama, di dalam dan dengan Allah, Sang Ilahi guna mewujudkan kerukunan dan keharmonisan ditengah perbedaan yang ada; sebuah upaya untuk mewujudkan keutuhan gambar dan rupa Allah. ${ }^{17}$

\section{KESIMPULAN}

Di tengah suburnya intoleransi dan diskriminasi yang terjadi di Indonesia, semua pihak berhak dan wajib mengupayakan kerukunan dan keharmonisan dalam beragama, walaupun perbedaan pemahaman adalah sebuah keniscayaan yang tidak dapat dihindari. Gereja perlu mengambil bagian dalam upaya tersebut. Deklarasi Nostra Aetate adalah sebuah tawaran alternatif yang dapat diambil di Indonesia guna menyampaikan kasih Allah kepada manusia melalui beberapa cara: (1) Dalam mengomunikasikan iman di ruang publik, hendaknya orang Kristen (gereja) menekankan sikap pastoral, bukan dogmatik; (2) menjadikan titik temu teologis sebagai sebuah kekuatan, bukan titik bedanya; (3) menjadi orang beragama yang berakar dalam pemahaman Kitab suci sehingga mampu berdialog dengan tingkat tinggi; (4) para pemuka agama mendorong umat untuk melupakan peristiwa-peristiwa konflik kegamaan yang sudah berlalu, dan dengan tulus hati melatih diri untuk memahami satu dengan yang lain dalam upaya membela dan mengembangkan keadilan sosial bagi sesama; (5) Negara menjalankan UUD 1945 pasal 29 dengan cara mengakomodasi dan menfasilitasi setiap umat beragama dan kepercayaan apapun untuk bebas beribadah selama mereka dapat menjaga keharmonisan umat beragama. Dari kelima cara inilah, diharapkan tercipta sebuah kerukunan dan keharmonisan beragama dalam wujud saling menghargai perbedaan yang ada tanpa harus terjadi pergesekan yang berdampak kepada sikap dan tindakan yang destruktif (intoleransi dan diskriminasi).

\section{REFERENSI}

Agama, Kementrian. "Kemenag Dan Kemenlu Sinergi Kenalkan Moderasi Beragama Ke Dunia." Accessed May 8, 2021. https://kemenag.go.id/read/kemenag-dan-kemenlu-sinergikenalkan-moderasi-beragama-ke-dunia-jjk2r.

Assyaukanie, Luthfi. "Akar-Akar Legal Intoleransi Dan Diskriminasi Di Indonesia." MAARIF 13, no. 2 (December 20, 2018): 27-42.

D'Costa, Gavin. Christianity and World Religions: Disputed Questions in the Theology of Religions. Chichester, U.K. ; Malden, Mass: Wiley-Blackwell, 2009.

developer, mediaindonesia com. "Kasus Intoleransi di Indonesia Jadi Sorotan Internasional." Last modified May 30, 2018. Accessed May 8, 2021.

https://mediaindonesia.com/internasional/163651/kasus-intoleransi-di-indonesia-jadisorotan-internasional.

Haryani, Elma. "Intoleransi Dan Resistensi Masyarakat Terhadap Kemajemukan: Studi Kasus Kerukunan Beragama Di Kota Bogor, Jawa Barat." Harmoni 18, no. 2 (December 31, 2019): 73-90.

${ }^{17}$ Reid Locklin, "One Text, Two Declarations: Theological Trajectories from Nostra Aetate," Theological Studies 78, no. 1 (March 2017): 49-71. 
Institute, Setara. "Memahami Situasi Intoleransi." Setara Institute, n.d. Accessed May 7, 2021. https://setara-institute.org/memahami-situasi-intoleransi/.

Locklin, Reid. "One Text, Two Declarations: Theological Trajectories from Nostra Aetate." Theological Studies 78, no. 1 (March 2017): 49-71.

Media, Kompas Cyber. "Imparsial: Intoleransi Masih Jadi Masalah yang Terus Berulang di Indonesia." KOMPAS.com. Last modified November 17, 2019. Accessed May 8, 2021. https://nasional.kompas.com/read/2019/11/17/16015521/imparsial-intoleransi-masih-jadimasalah-yang-terus-berulang-di-indonesia.

Novalina, Dr Martina. Di Bawah Kepak Sayap Sang Garuda: Pemahaman, Sikap dan Tindakan Fundamental Keber-Agama-An Dalam Bingkai Pancasila. Martina publisher, 2018.

Novalina, Martina. "Spiritualitas Orang Kristen Dalam Menghadirkan Kerajaan Allah Di Tengah Tantangan Radikalisme." Jurnal Teologi Kontekstual Indonesia 1, no. 1 (June 29, 2020): 26.

R. Hardawiryana. "Seri Dokumen Gerejawi No. 10: Dignitatis Humanae - Nostra Aetate." Departemen Dokumentasi dan Penerangan KWI, 2013. Accessed May 8, 2021. http://www.dokpenkwi.org/wp-content/uploads/2020/01/Seri-Dokumen-GerejawiDIGNITATIS-HUMANAE-NOSTRA-AETATE.pdf.

Sanusi, Irfan, and Enjang Muhaemin. "Intoleransi Keagamaan Dalam Framing Surat Kabar Kompas." Communicatus: Jurnal IImu komunikasi 3, no. 1 (June 25, 2019): 17-34.

Zaluchu, Sonny Eli. "Metode Penelitian Di Dalam Manuskrip Jurnal Ilmiah Keagamaan." Jurnal Teologi Berita Hidup 3, no. 2 (March 2021): 249-266.

"Memperkuat Kerukunan Melalui Dialog - Kanwil Kementerian Agama Provinsi Nusa Tenggara Timur." Accessed May 8, 2021. https://ntt.kemenag.go.id/berita/510490/memperkuatkerukunan-melalui-dialog.

"Vonis penjara Ahok lewat kaca mata media internasional." BBC News Indonesia, 2021. Accessed May 8, 2021. https://www.bbc.com/indonesia/dunia-39855994. 